\title{
The Effects of Nano Alumina On Mechanical Properties of Room Temperature Vulcanized Maxillofacial Silicone (Pilot Study)
}

\author{
Ahmed Aj. AbdulKareem, B.D.S. ${ }^{(1)}$ \\ Thekra I. Hamad, B.D.S, M.Sc. Ph.D ${ }^{(2)}$
}

\begin{abstract}
Background: Facial disfigurement can be the result of a congenital anomaly, trauma or tumor surgery, in many cases the prosthetic rehabilitation is indicated. Maxillofacial prosthetic materials should have desirable and ideal physical, aesthetic, and biological properties and those properties should be kept for long period of time in order to reach patient acceptance. Silicone elastomer are the most commonly used material for facial restoration because of its favorable properties mechanically and physically as the biocompatibility and good elasticity.

Aim of this study: This study aimed to evaluate the effect of addition of Aluminum oxide $\left(\mathrm{Al}_{2} \mathrm{O}_{3}\right) \mathrm{Nano}$ fillers in different concentrations on tear strength and hardness of VST 50F room temperature vulcanized maxillofacial silicone. Methods: The Nano $\mathrm{Al}_{2} \mathrm{O}_{3}$ was added in a concentrations of $0.5 \%, 1 \%, 1.5 \%$ and $2 \%$ by weight to the VST $50 \mathrm{~F}$ RTV maxillofacial silicone, the samples were tested for tear strength (ISO $34-1$ ) and shore A hardness (ISO 7619), the FTIR was used to analyze the interaction of the $\mathrm{Nano} \mathrm{Al}_{2} \mathrm{O}_{3}$ with the silicone. The data were analyzed using descriptive and inferential statistics. One-way ANOVA test was used to test the changing significance.

Results: There was no interaction between the Nano- $\mathrm{Al}_{2} \mathrm{O}_{3}$ and the silicone in the FTIR. The results showed highly significant increase in tear strength and shore A hardness for the $1 \%$ and $1.5 \%$ concentration groups when Compared to control group.

Conclusion: The reinforcement of VST 5OF maxillofacial silicone with $1 \%$ and $1.5 \%$ concentrations of $\mathrm{NanO} \mathrm{Al}_{2} \mathrm{O}_{3}$
\end{abstract} improved some of the mechanical properties of the room temperature vulcanized silicone.

Keywords: RTV maxillofacial silicone, $\mathrm{NanO}_{2} \mathrm{O}_{3}$, tear strength, shore A hardness. (Received: 29/7/2019; Accepted: $1 / 9 / 2019)$

\section{INTRODUCTION}

The first part of the body that will contact the world is the face, the accepted appearance of the face is now became mandatory to be accepted in a job, appear in magazine or television and in marriage looking. Surgical reconstruction of the facial defects may not be possible owing to size or location of the defect, the patient's medical condition or personal desires may also preclude reconstructive surgery. In such cases, prosthetic rehabilitation is indicated ${ }^{(1)}$.

Some Nano fillers are added to the matrix of maxillofacial silicone to improve its properties, as in the addition of titanium silicate which resulted in improvement of the mechanical properties of the RTV maxillofacial silicone ${ }^{(2)}$. The aluminum oxide $\left(\mathrm{Al}_{2} \mathrm{O}_{3}\right)$ as a Nano-fillers characterized by its fair chemical inertness, its strength and stiffness among other ceramic oxides and by a preferable dielectric properties and refractoriness (3).

\footnotetext{
1. M.Sc. Student (Prosthodontics Department, College of Dentistry/ University of Baghdad, Iraq)

2. Prof. (Prosthodontics Department, College of Dentistry/

University of Baghdad, Iraq)

Corresponding author: Dr. Ahmed Abdul Jaleel E-mail: sl.sl91@yahoo.com
}

The aim of this study was to evaluate the effect of addition of different concentrations $(0.5 \%, 1 \%$, $1.5 \%$ and $2 \%$ ) by weight of $\mathrm{Al}_{2} \mathrm{O}_{3}$ Nano-fillers on tear strength and shore A hardness of VST 50F RTV maxillofacial silicone.

\section{MATERIALS AND METHODS}

The materials used in this study listed in (Table 1).

Table 1: The study materials

\begin{tabular}{|c|c|c|}
\hline Material & Manufacturer & $\begin{array}{c}\text { Patch } \\
\text { number }\end{array}$ \\
\hline $\begin{array}{l}\text { VST 50F RTV } \\
\text { maxillofacial } \\
\text { silicone elastomer }\end{array}$ & $\begin{array}{l}\text { Factor II Inc., } \\
\text { USA }\end{array}$ & $\begin{array}{c}\text { B } \\
101918- \\
1 \mathrm{LB}\end{array}$ \\
\hline $\begin{array}{l}\text { Aluminum Oxide } \\
\text { Nano fillers } \\
99.5 \% \text { purity, } 40- \\
60 \mathrm{~nm} .\end{array}$ & $\begin{array}{l}\text { US research } \\
\text { nanomaterials } \\
\text { inc., USA }\end{array}$ & $\begin{array}{c}1344- \\
28-1\end{array}$ \\
\hline
\end{tabular}

Two main groups were prepared, one for the tear strength test and the other for the hardness test, in each one of them a 25 samples were fabricated, each main group subdivided into five subgroups which are the control group $0 \%$ (without Nano addition), $0.5 \%, 1 \%, 1.5 \%$ and 
$2 \%$ by weight $\mathrm{Nano} \mathrm{Al}_{2} \mathrm{O}_{3}$ addition groups, each of them had 5 samples. Plastic molds were fabricated using CNC machine, each mold consists of base, frame and cover parts in the same dimensions.

The maxillofacial silicone type used in this study was the VST 50F room temperature vulcanized one which is a two parts silicone, the mixing ratio of the base to the catalyst was 10:1 according to the manufacturer instructions, the mixing of the control group began with the addition of the base to the electronic balance container then the catalyst was added and started mixing by the vacuum mixer with a speed of $360 \mathrm{rpm}$ and a vacuum was of (-10 bar), for the reinforced groups the Nano powder was added to the electronic balance container followed by addition of the base then starting mixing without vacuum for 3 minutes followed by mixing with a vacuum for 7 minutes followed by catalyst addition and mixing with vacuum for the remaining 5 minutes ${ }^{(4)}$.

The silicone became ready to be poured in the molds of tear strength test and hardness test, followed by tighten the cover with the remaining molds parts by the G-clamps. After 24 hours of complete vulcanization of the RTV silicone the mechanical properties were tested. The tear strength calculated using the following formula according to the ASTM D624 (2012) ${ }^{(5)}$ :

$$
\begin{aligned}
& \text { Tear strength } \\
& =\frac{\mathrm{F}(\text { Maximum force at breakage }(\mathrm{KN}))}{D(\text { thickness of the sample }(\mathrm{m}))}
\end{aligned}
$$

A samples with flat ends and a right angle at the middle. While the hardness test was done by a digital shore A hardness durometer device according to ASTM D2240-05 (6), a samples with a length of $25 \mathrm{~mm}$ and a width of $25 \mathrm{~mm}$ and a thickness of $6 \mathrm{~mm}$ were fabricated.

\section{RESULTS}

The statistical results of tear strength test showed a highly significant increase in $1 \%$ and $1.5 \%$ groups by doing the one way ANOVA test and found that the $\mathrm{P}$ values $<0.05$. The results of shore A hardness tests showed an increasing in all reinforcement groups except in $0.5 \%$ group when compared to the $0 \%$ group by doing the one way ANOVA test and found that the $\mathrm{P}$ value $<0.05$ (Table 2 and 3).
Table 2: Statistical test of Tear strength

\begin{tabular}{|c|c|c|c|c|c|c|}
\hline Groups & $\begin{array}{c}\text { Minim } \\
\text { um }\end{array}$ & $\begin{array}{l}\text { Maxi } \\
\text { mum }\end{array}$ & $\begin{array}{c}\text { Mea } \\
\mathbf{n}\end{array}$ & \pm SD & $\mathbf{F}$ & $\begin{array}{c}\mathbf{P} \\
\text { valu } \\
\mathbf{e}\end{array}$ \\
\hline $\begin{array}{c}0 \% \\
\mathrm{Al}_{2} \mathrm{O}_{3} \\
\end{array}$ & 25.5 & 25.7 & 25.6 & 0.22 & \multirow[t]{5}{*}{$\begin{array}{r}116 \\
.63\end{array}$} & \multirow[t]{5}{*}{.001} \\
\hline $\begin{array}{l}0.5 \% \\
\mathrm{Al}_{2} \mathrm{O}_{3}\end{array}$ & 25 & 25.2 & 25.1 & 0.31 & & \\
\hline $\begin{array}{r}1 \% \\
\mathrm{Al}_{2} \mathrm{O}_{3} \\
\end{array}$ & 26 & 26.6 & 26.2 & 0.26 & & \\
\hline $\begin{array}{l}1.5 \% \\
\mathrm{Al}_{2} \mathrm{O}_{3} \\
\end{array}$ & 27.9 & 28.4 & 28.2 & 0.22 & & \\
\hline $\begin{array}{c}2 \% \\
\mathrm{Al}_{2} \mathrm{O}_{3}\end{array}$ & 26.4 & 26.8 & 26.6 & 0.14 & & \\
\hline
\end{tabular}
(N/mm)

Table 3: Statistical test of the Shore A

\begin{tabular}{|c|c|c|c|c|c|c|}
\hline Groups & $\begin{array}{c}\text { Minim } \\
\text { um }\end{array}$ & $\begin{array}{l}\text { Maxi } \\
\text { mum }\end{array}$ & $\begin{array}{c}\text { Mea } \\
\mathbf{n}\end{array}$ & \pm SD & $\mathbf{F}$ & $\begin{array}{c}\mathbf{P} \\
\text { value }\end{array}$ \\
\hline $\begin{array}{c}0 \% \\
\mathrm{Al}_{2} \mathrm{O}_{3}\end{array}$ & 27.3 & 27.9 & 27.4 & 0.4 & \multirow[t]{5}{*}{$\begin{array}{l}50 \\
0.7\end{array}$} & \multirow[t]{5}{*}{0.000} \\
\hline $\begin{array}{l}0.5 \% \\
\mathrm{Al}_{2} \mathrm{O}_{3}\end{array}$ & 26.5 & 26.9 & 26.7 & 0.23 & & \\
\hline $\begin{array}{c}1 \% \\
\mathrm{Al}_{2} \mathrm{O}_{3}\end{array}$ & 27.5 & 27.7 & 27.6 & 0.3 & & \\
\hline $\begin{array}{l}1.5 \% \\
\mathrm{Al}_{2} \mathrm{O}_{3}\end{array}$ & 28 & 28.5 & 28.3 & 0.3 & & \\
\hline $\begin{array}{c}2 \% \\
\mathrm{Al}_{2} \mathrm{O}_{3}\end{array}$ & 34.5 & 34.9 & 34.6 & 0.3 & & \\
\hline
\end{tabular}
hardness (IU)

There was no any interaction between the $\mathrm{Al}_{2} \mathrm{O}_{3}$ Nano fillers and the VST 50F maxillofacial silicone in the FTIR analysis (Figures 1\&2). 


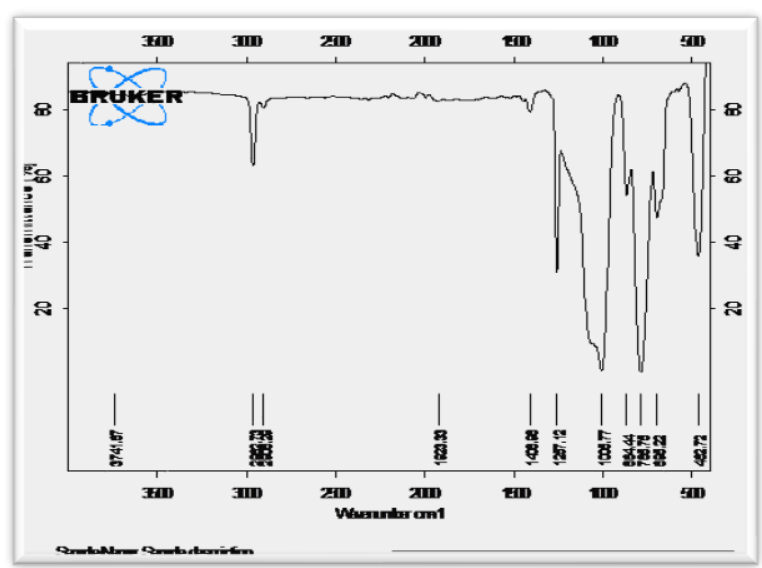

Figure 1: the FTIR of the VST 50F maxillofacial silicone before addition of $\mathrm{Al}_{2} \mathrm{O}_{3}$ Nano fillers

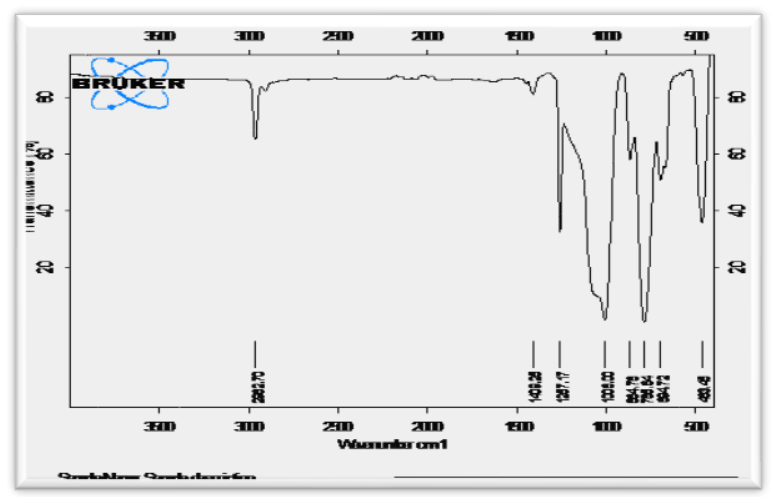

Figure 2: the FTIR of the VST 50F maxillofacial silicone after addition of $\mathrm{Al}_{2} \mathrm{O}_{3}$ Nano fillers

\section{DISCUSSION}

Many previous studies results showed that the addition of fillers in a Nano scale improved the mechanical properties of the maxillofacial silicone, so the Aluminum oxide Nano fillers were chosen to be added because it had many preferable properties when compared to other Nano filler types ${ }^{(3)}$.

The results showed an increase in tear strength after reinforcement except for the $0.5 \%$ and $2 \%$ reinforcement groups, that may be due to the ability of the Nanoparticles to be trapped within the silicone matrix and in some polymer chains and then a 3D mesh formation would result in a physical interaction which my lead to increase the density of the silicone and the resistance to tear ${ }^{(7)}$. For the decrease in tear strength in the $0.5 \%$ this may be due to the very small amounts of fillers which act as impurities that would affect the polymerization process of the silicone without formation a 3D mesh ${ }^{(8)}$, while for the decrease in tear strength in the $2 \%$ group this may be caused by beginning of fillers to agglomerate in the silicone matrix with the increasing in concentration of added fillers which may results in restriction of flow and movement of the polymer matrix when the stretching forces increased ${ }^{(9)}$

shore A hardness also increased for the reinforced samples which may be due to The filler adherence to each other when increasing the filler concentrations made it fill the inter-aggregate areas within the silicone matrix so it will resist the indentation loads ${ }^{(10)}$. For the reduction in the $0.5 \%$ group may be due to the small amounts of the Nano fillers added which would be as an impurities and interact with the polymerization process of the silicone ${ }^{(8)}$.

\section{CONCLUSIONS}

The reinforcement of VST 50F RTV maxillofacial silicone with $1 \%$ and $1.5 \% \mathrm{Nano}_{2} \mathrm{Al}_{3}$ improved some of the mechanical properties of silicone with the best improvement occur after 1\% and 1.5\% Nano $\mathrm{Al}_{2} \mathrm{O}_{3}$ reinforcement.

\section{REFERENCES}

1. MALLER, U. S., KARTHIK, K. \& MALLER, S. V. (2010). "Maxillofacial prosthetic materials-past and present trends". JIADS, 1(2), 25-30.

2. ALSMAEL, M. A., \& ALI, M. M. M. (2018). "The Effect of Nano Titanium Silicate Addition on Some Properties of Maxillofacial Silicone Material". JOURNAL OF RESEARCH IN MEDICAL AND DENTAL SCIENCE, 6(5), 127-132.

3. Saritha MK, Shadakshari S, Nandeeshwar DB, Tewary S. An in vitro study to investigate the flexural strength of conventional heat polymerised denture base resin with addition of different percentage of aluminium oxide powder. Asian J Med Clin Sci. 2012;1(2):80-5.

4. Tukmachi M, Moudhaffer M. Effect of nano silicon dioxide addition on some properties of heat vulcanized maxillofacial silicone elastomer. JPBS. 2017;12(3-4):37-43.

5. $\quad$ ASTM D624-00, (2012). "Standard Test Method for Tear Strength of Conventional Vulcanized Rubber and Thermoplastic Elastomers". ASTM International, West Conshohocken, PA, USA.

6. ASTM D2240-05, (2010). " standard test method for rubber Property-Durometer hardness". ASTM International, West Conshohocken, PA, USA.

7. Harper CA. Handbook of plastics, elastomers, and composites. New York: McGraw-Hill; 2002 Jun.

8. Guiotti, A.M., Goiato, M.C., dos Santos, D.M., Vechiato-Filho, A.J., Cunha, B.G., Paulini, M.B., 
Moreno, A., de Almeida, M.T.G., 2015. "Comparison of conventional and plant-extract disinfectant solutions on the hardness and color stability of a maxillofacial elastomer after artificial aging". J Prosthet Dent.

9. ZAYED, S. M., ALSHIMY, A. M. \& FAHMY, A. E. (2014). "Effect of surface treated silicon dioxide nanoparticles on some mechanical properties of maxillofacial silicone elastomer". Int J Biomater, 2014, 750398-750405.
10. Alsmael MA, Ali MM. The Effect of Nano Titanium Silicate Addition on Some Properties of Maxillofacial Silicone Material. JOURNAL OF RESEARCH IN MEDICAL AND DENTAL SCIENCE. 2018 Jan 1;6(5):127-32.

الخلاصة.

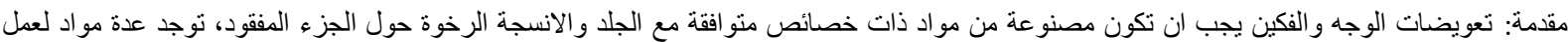

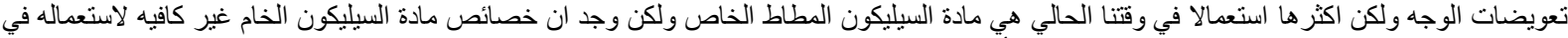

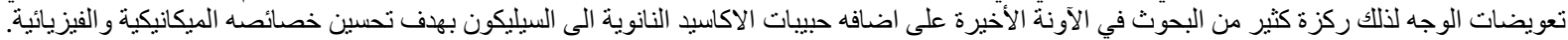

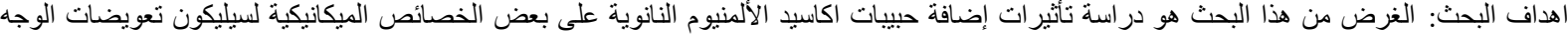

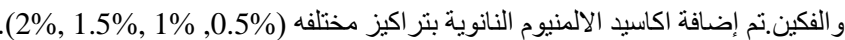

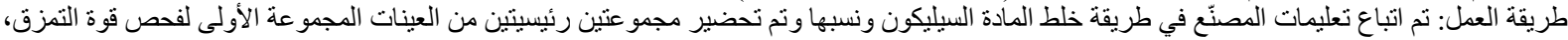

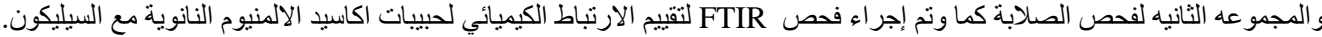

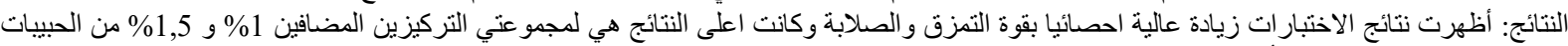

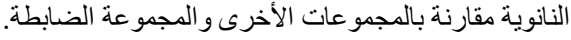
الاستتاجات: نستنتج بان إضافة حبيبات اكاسيد الالمنيوم النانوية إلى مادة السيليكون المطاط عزز بعض الخو اص الميكانيكية لهذه المادة. 